\title{
Brachial plexus cyst in a patient with multifocal motor neuropathy
}

\author{
Cisto do plexo braquial num doente com neuropatia motora multifocal \\ Ana Paula Sousa', Pedro Alves², Bruno Maia', Luisa Medeiros³
}

A 61-year-old woman was followed for multifocal motor neuropathy (MMN) with conduction block since young adulthood. She had bilateral clinical and neurophysiologic involvement of both median and ulnar nerves, as also the right peroneal nerve. In a recent reevaluation, we decided to complete her investigation with a brachial plexus magnetic resonance imaging (MRI) that, besides diffuse thickening of the right brachial plexus trunks, showed a round hyperintense cyst that compressed several branches distally (Figure). Brachial plexus MRI may be important in MMN not only to support diagnosis ${ }^{1,2}$ but also to exclude other pathologies that can worse the neurologic deficits.
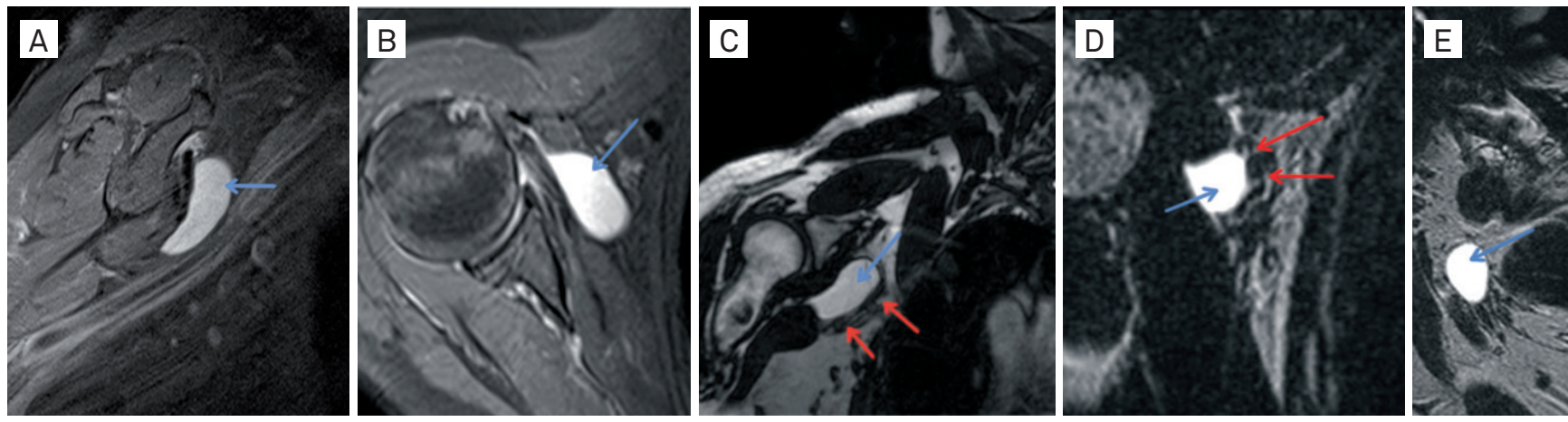

DP WI W/FAT SAT: Proton density weighted imaging with fat saturation. CISS: Constructive interference in the stady state.

Figure. Right brachial plexus magnetic resonance imaging. Unilocular paralabral cyst (blue arrows) from the anterior labrum with extraarticular growth compressing several branches of the right brachial plexus (red arrows). The cyst has a homogenous appearance with a thin capsule and displaces caudally the distal plexus components without invasive or aggressive features, at the subcoracoid space.

\section{References}

1. Meuth SG, Kleinschnitz C. Multifocal motor neuropathy: update on clinical characteristics, pathophysiological concepts and therapeutic options. Eur Neurol 2010;63:193-204.
2. Van Es HW, Van den Berg LH, Franssen H, et al. Magnetic resonance imaging of the brachial plexus in patients with multifocal motor neuropathy. Neurology 1997;48:1218-1224.

Study carried out at Centro Hospitalar de Lisboa Central, Entidade Pública Empresarial (EPE), Lisboa, Portugal.

'Neurology Resident, Neurology Department, Centro Hospitalar de Lisboa Central, EPE, Lisboa, Portugal;

${ }^{2}$ Radiology Consultant, Radiology Department, Centro Hospitalar de Lisboa Central, EPE, Lisboa, Portugal;

${ }^{3}$ Neurophysiology Consultant, Neurology Department, Centro Hospitalar de Lisboa Central, EPE, Lisboa, Portugal.

Correspondence: Ana Paula Sousa; Departamento de Neurologia do Centro Hospitalar de Lisboa Central; Rua José António Serrano 1150 / 199 ; Lisboa - Portugal;

E-mail:apdiogosousa@gmail.com

Conflict of interest: There is no conflict of interest to declare.

Received 14 October 2012; Received in final form 18 February 2013; Accepted 25 February 2013. 